\title{
$\nabla$ \\ IJCRR \\ Section: Healthcare \\ Analysis of the Results of a Study on the Frequency of Occurrence and Prevalence of Risk Factors for Chronic Kidney Disease
}

ISI Impact Factor

(2019-20): 1.628

IC Value (2019): 90.81

$\operatorname{SJIF}(2020)=7.893$

(c) (7) (3)

Copyright@IJCRR

\author{
Akhmedova Nilufar Sharipovna, Sulaimonova Gulnoz Tulkinzhanovna, \\ Mukhammedzhanova Mastura Hayatovna, Giyosova Nigora Odiljonovna
}

Bukhara State Medical Institute, Bukhara, Uzbekistan.

\section{ABSTRACT}

Introduction: Numerous studies have shown that in patients with chronic kidney disease (CKD), the clinical manifestations of this pathology often appear in an advanced stage of the disease when the patient needs pathogenetic therapy or substitution therapy. One of the necessary and important tasks of the preventive direction of nephrology is the identification and stratification of risk factors for the development and progression of CKD.

Objective: To survey the population permanently living in rural areas for the early detection of CKD.

Methods: Patients with microalbuminuria (MAU >10 mg/L), which persisted for 3 months or more were examined.

Results: It follows that screening studies for the detection of CKD in the rural population are justified. Besides, it seems to be the basis for primary prevention of CKD and the basis for the development of secondary prevention of CKD among rural residents. The next stage of research was clinical and laboratory studies in the identified contingent to establish an early diagnosis of CKD using simple, cheap, reliable, and effective laboratory diagnostic methods using urine analysis of the examined.

Conclusion: The first feature was that with the increasing age of the surveyed, the incidence of CKD significantly increases. The second feature is a gender difference, where the incidence of CKD was 2.2 times higher in women $(p<0.05)$ compared with men. The third feature was that almost all surveyed rural women who suffered nephropathy and/or arterial hypertension during pregnancy were not observed at the place of residence (in primary health care) after discharge from maternity complexes or perinatal centres.

Key Words: Chronic kidney disease, Microalbuminuria, Glomerular filtration rate, Nephropathy of pregnancy, Arterial hypertension of pregnant women

\section{INTRODUCTION}

Screening is a secondary prevention measure aimed at detecting a specific disease in the preclinical stage. During the screening, a mass examination of the contingent from certain risk groups is carried out, who do not consider themselves sick, do not seek medical help, and accordingly, do not receive a specific treatment. The main goal of screening is to detect the disease before specific clinical symptoms appear and to completely cure the pathology. 1,2

It should be emphasized that the works provided by screening studies in rural areas of our republic are rare. In this regard, we considered it expedient to survey the population permanently living in rural areas for the early detection of CKD. ${ }^{3,4}$
One of the necessary and important tasks of the preventive direction of nephrology is the identification and stratification of risk factors for the development and progression of CKD.

In the conceptual model of $\mathrm{CKD}$, several risk factor groups are distinguished:

- risk factors for the development and progression of CKD;

- modifiable and non-modifiable factors;

- traditional and non-traditional.

However, the classification of factors seems to be controversial. It is especially difficult to draw the line between the factors of development and progression of CKD. It has now been proven that most of the traditional risk factors for cardiovascular disease are also risk factors for CKD. These

\section{Corresponding Author:}

Akhmedova Nilufar Sharipovna, Bukhara State Medical Institute, Bukhara, Uzbekistan.

ISSN: 2231-2196 (Print)

Received: 16.08 .2020
ISSN: 0975-5241 (Online)

Revised: 20.10 .2020
Accepted: 08.11 .2020
Published: 16.01 .2021 
include arterial hypertension, diabetes mellitus, dyslipoproteinemia, anaemia, metabolic syndrome, age, etc. ${ }^{5}$

\section{MATERIALS AND METHODS}

The main selection criterion was microalbuminuria (MAU> $10 \mathrm{mg} / \mathrm{L}$ ), which persisted for 3 months or more, considering this parameter as a diagnostic predictor of CKD development. Among the surveyed, this criterion of CKD was detected in 317 persons $(29.1 \pm 1.6 \%)$ out of 1087 , note that there were 2.8 times more women than men $-68.8 \pm 4.6 \%$, respectively $(\mathrm{n}=218)$ and $31.2 \pm 3.1 \%(\mathrm{n}=99)$. This fact indicates that our data differ from other authors who indicate that the risk factor for the development of CKD belongs to the male sex. ${ }^{6,7}$

\section{RESULTS AND DISCUSSION}

Based on clinical materials, parameters of laboratory and instrumental studies, a diagnosis was made in some of the subjects. The number of examined and identified nosological units differed in the same way as 1 examined person sometimes had 2 or 3 diagnoses of the disease. Thus, in 210 patients with diagnoses established based on data from outpatient records, there were 351 diseases ( 1.67 nosologies per 1 examined). The contingent with the diagnosis established after our survey $(\mathrm{n}=107)$ had 167 nosologies -1.56 per 1 examined, respectively, the data in Table 1 were calculated from the total number of identified nosological units.

Table 1: Indicators of the incidence of various pathologies which were risk factors for the development of chronic kidney disease

\begin{tabular}{lcc} 
Nosological units & \multicolumn{2}{c}{ Diagnosis } \\
& $\begin{array}{c}\text { based on outpa- } \\
\text { tient cards } \\
351 \text { nosologies }\end{array}$ & $\begin{array}{c}\text { After examination } \\
167 \text { nosologies }\end{array}$ \\
$\begin{array}{l}\text { Arterial hyperten- } \\
\text { sion }\end{array}$ & $148 / 42.17 \pm 4.93$ & $56 / 33.54 \pm 4.72^{*} \downarrow$ \\
Cardiac ischemia & $54 / 15.38 \pm 3.60$ & $26 / 15.57 \pm 3.62 \downarrow$ \\
Diabetes & $31 / 8.83 \pm 2.83$ & $8 / 4.79 \pm 2.13^{*} \downarrow$ \\
$\begin{array}{l}\text { Rheumatological } \\
\text { diseases }\end{array}$ & $27 / 7.69 \pm 2.66$ & $7 / 4.19 \pm 2.0 \downarrow$ \\
$\begin{array}{l}\text { Anaemia of vary- } \\
\text { ing degrees }\end{array}$ & $25 / 7.12 \pm 2.57$ & $6 / 3.59 \pm 1.86^{*} \downarrow$ \\
Endemic goitre & $10 / 2.85 \pm 1.66$ & $4 / 2.40 \pm 1.53 \downarrow$ \\
$\begin{array}{l}\text { Obesity } \\
\begin{array}{l}\text { Diseases of the } \\
\text { urinary tract }\end{array}\end{array}$ & $51 / 1.42 \pm 1.18$ & $31 / 18.56 \pm 3.88^{*} \downarrow$ \\
\hline
\end{tabular}

Note: absolute in the numerator, relative (\%) indicators in the denominator: *significant difference in the parameter; $\uparrow \downarrow$ and $\leftrightarrow$ - increase, decrease or no difference between the indicator and the compared group.
Among the diagnoses established, both on the basis of outpatient records and after examination, diseases of the cardiovascular system were often encountered, with arterial hypertension, respectively, $42.17 \pm 4.93 \%(\mathrm{n}=148)$ and $33.54 \pm$ $4.72 \%(\mathrm{n}=56)$, ischemic heart disease, respectively $15.38 \pm$ $3.60 \%(\mathrm{n}=54)$ and $15.57 \pm 3.62 \%(\mathrm{n}=26)$, primary urinary tract disease, respectively, $14.53 \pm 3.52 \%(\mathrm{n}=51)$ and 17.37 $\pm 3.78 \%(\mathrm{n}=29)$.

Other established diagnoses were less common - diabetes mellitus, respectively, $8.83 \pm 2.83 \%(\mathrm{n}=31)$ and $4.79 \pm$ $2.13 \%(\mathrm{n}=8)$; rheumatic diseases, respectively $7.69 \pm 2.66 \%$ $(n=27)$ and $4.19 \pm 2.0 \%(n=7)$; anemia, respectively, 7.12 $\pm 2.57 \%(\mathrm{n}=25)$ and $3.59 \pm 1.86 \%(\mathrm{n}=6)$; endemic goiter, respectively $2.85 \pm 1.66 \%(\mathrm{n}=10)$ and $2.40 \pm 1.53 \%(\mathrm{n}=$ 4); obesity, respectively, $1.42 \pm 1.18 \%(n=5)$ and $17.37 \pm$ $3.78 \%(\mathrm{n}=31)$.

We can say that among the above diseases, the level of obesity diagnosis as a nosological unit is very low - the difference between the groups is 6.2 times. This indicates that health professionals do not rate obesity as an unfavourable risk factor for the development and various pathological conditions, including CKD.

Considering the importance of urinary tract diseases as risk factors for the development of CKD, we decided to cite the frequency of occurrence of these nosological units separately (Table 2).

Table 2: Indicators of the incidence of urinary tract diseases as risk factors for the development of CKD in the surveyed rural contingent

\begin{tabular}{|c|c|c|}
\hline \multirow[b]{2}{*}{ Nosological units } & \multicolumn{2}{|c|}{ Diagnosis } \\
\hline & $\begin{array}{l}\text { based on out- } \\
\text { patient cards } \\
\text { 5mosologies }\end{array}$ & $\begin{array}{c}\text { After examination } \\
29 \text { nosologies }\end{array}$ \\
\hline Pyelonephritis & $24 / 47.06 \pm 4.99$ & $16 / 55 \cdot 17 \pm 4 \cdot 97^{* \uparrow}$ \\
\hline $\begin{array}{l}\text { Cystitis (acute and } \\
\text { chronic) }\end{array}$ & $18 / 35 \cdot 29 \pm 4 \cdot 77$ & $7 / 24.14 \pm 4.27^{*} \downarrow$ \\
\hline Urolithiasis disease & $7 / 13.73 \pm 3.44$ & $6 / 20.69 \pm 4.05 \leftrightarrow$ \\
\hline Glomerulonephritis & $2 / 3.92 \pm 1.94$ & o \\
\hline
\end{tabular}

It should be noted that among the surveyed with an established diagnosis based on the data of outpatient cards, the establishment of the diagnosis of CKD as a nosological unit was not identified. After the survey, this diagnosis was made in $29.1 \%(n=21)$ of the general surveyed respondents.

In our studies, the role of each nosological unit listed in Table 2 as a risk factor for the development of CKD is insignificant, so we decided to use the general group of urinary tract diseases to determine the groups according to the risk of developing CKD. 
Conducted scientific studies prove that hypertension, diabetes mellitus, and obesity are traditional factors in the development of CKD ${ }^{3}$. However, in the development of chronic kidney damage, non-traditional factors in the development of CKD are of great importance. The results of our research show that these factors include: the place of residence (city or village), ethnic customs of the people, lifestyle, and standard of living of the population, the effectiveness of preventive measures carried out by medical institutions for widespread non-infectious chronic diseases, the use of poorquality drinking water, violation rules of rational nutrition, the constant use of high-calorie food by the population.

According to Valerie and Kathrin (2017), studies were carried out in Switzerland, many of the factors we indicated were the main causes of the spread of CKD among the population. Thus, it was found that there is a significant difference between the diagnoses established based on outpatient cards of rural family polyclinics and after our examination. Besides, there were 1.67 nosologies for 1 patient with a diagnosis established based on outpatient cards, and after our studies, this figure was 1.56 nosologies. Among the frequently encountered diseases, there were also diseases of the urinary tract (pyelonephritis, cystitis, urolithiasis, glomerulonephritis) $-16.09 \%$ (51 out of 317 examined). It was revealed that each separately the role of these nosologies as risk factors for the development of CKD was insignificant. Arterial hypertension, diabetes mellitus, obesity, and diseases of the urinary tract, which were among the main risk factors for the development of CKD, were insufficiently identified in terms of the primary and repeated referral of patients for medical help.

Based on this, to determine the frequency of occurrence of manageable risk factors affecting the development and progression of $\mathrm{CKD}$, the following factors were analyzed by the integration method:

- abuse of nephrotoxic drugs that are usually sold without a prescription in our country - analgesics, nonsteroidal anti-inflammatory drugs (NSAIDs), some antibiotics;

- abuse of salty and bitter foods;

- bad habits - smoking, alcohol intake;

- not controlling pathological conditions and diseases with a burdened history (proteinuria, dysuria, nephropathy of pregnant women, hypertension of pregnant women, acute allergic reactions, acute bleeding with hypovolemia);

- chronic foci of infection - chronic tonsillitis, chronic otitis media, dental caries.

When analyzing the frequency of occurrence of these factors, we paid attention to the level of identification and / or elimination of these factors as the cause of the development of other diseases (Table 3).
Table 3: Frequency of occurrence of controllable risk factors for CKD development among the examined individuals

\begin{tabular}{|c|c|c|c|}
\hline \multirow{2}{*}{\multicolumn{2}{|c|}{ Unconventionalfactors }} & \multicolumn{2}{|c|}{ Diagnosis } \\
\hline & & $\begin{array}{l}\text { based on out- } \\
\text { patient cards } \\
51 \text { nosologies }\end{array}$ & $\begin{array}{c}\text { After examina- } \\
\text { tion } \\
29 \text { nosologies }\end{array}$ \\
\hline \multicolumn{2}{|c|}{$\begin{array}{l}\text { Abuse of nephrotoxic } \\
\text { drugs }\end{array}$} & $123 / 58.57 \pm 4.92$ & $67 / 62.61 \pm 4.83 \leftrightarrow$ \\
\hline \multicolumn{2}{|c|}{$\begin{array}{l}\text { Abuse of salty and bitter } \\
\text { foods }\end{array}$} & $71 / 33.80 \pm 4.73$ & $46 / 42.99 \pm 4.95 \leftrightarrow$ \\
\hline \multicolumn{2}{|l|}{ Bad habits } & $45 / 21.42 \pm 4.1$ & $44 / 41.12 \pm 4.92^{* \uparrow}$ \\
\hline \multicolumn{2}{|c|}{ A history of proteinuria } & $44 / 20.95 \pm 4.16$ & $41 / 38.31 \pm 4.86^{* \uparrow}$ \\
\hline \multicolumn{2}{|c|}{$\begin{array}{l}\text { Dysuria of unclear aetiol- } \\
\text { ogy in history }\end{array}$} & $92 / 43.80 \pm 4.96$ & $42 / 39.2 \pm 4.88 \leftrightarrow$ \\
\hline \multicolumn{2}{|c|}{$\begin{array}{l}\text { Nephropathy of } \\
\text { pregnancy^ }^{\wedge}\end{array}$} & $81 / 60.90 \pm 4.87$ & 51/6o.0 $\pm 4.89 \leftrightarrow$ \\
\hline \multicolumn{2}{|c|}{$\begin{array}{l}\text { Arterial hypertension } \\
\text { during pregnancy^ }\end{array}$} & $52 / 39.09 \pm 4.87$ & $34 / 40.0 \pm 4.89 \leftrightarrow$ \\
\hline \multicolumn{2}{|c|}{$\begin{array}{l}\text { History of acute allergic } \\
\text { reactions }\end{array}$} & $5 / 2.38 \pm 1.52$ & $14 / 13.08 \pm 3.37^{*} \uparrow$ \\
\hline \multicolumn{2}{|c|}{$\begin{array}{l}\text { History of acute bleeding } \\
\text { or hypovolemic shock }\end{array}$} & $6 / 2.85 \pm 1.66$ & $5 / 4.67 \pm 2.10 \leftrightarrow$ \\
\hline \multirow{3}{*}{$\begin{array}{l}\text { The presence } \\
\text { of chronic } \\
\text { foci of infec- } \\
\text { tion }\end{array}$} & $\begin{array}{l}\text { Chronic } \\
\text { tonsillitis }\end{array}$ & $67 / 31.90 \pm 4.66$ & $41 / 38.31 \pm 4.86 \leftrightarrow$ \\
\hline & $\begin{array}{l}\text { Chronic } \\
\text { otitis } \\
\text { media }\end{array}$ & $4 / 1.90 \pm 1.36$ & $6 / 5.60 \pm 2.29 \leftrightarrow$ \\
\hline & $\begin{array}{l}\text { Tooth } \\
\text { decay }\end{array}$ & $123 / 58.57 \pm 4.92$ & $\begin{array}{c}69 / 64.48 \pm 4.78 \\
\leftrightarrow\end{array}$ \\
\hline
\end{tabular}

Note: ^indicators are calculated by the number of surveyed women in groups, respectively, $\mathrm{n}=133$ and $\mathrm{n}=85$; *significant difference in the parameter; $\uparrow \downarrow$ and $\leftrightarrow$ - increase, decrease or no difference between the indicator and the compared group.

Among the controllable risk factors for the development of CKD, the abuse of nephrotoxic drugs (analgesics, NSAIDs, antibiotics), respectively, $58.57 \pm 4.92 \%(\mathrm{n}=123)$ and 62.61 $\pm 4.83 \%(n=67)$ were common; the presence of chronic foci of infection, of which a large number of dental caries were detected $58.57 \pm 4.92 \%(n=123)$ and $64.48 \pm 4.78 \%(n=$ 69), followed by chronic tonsillitis $31.90 \pm 4.66 \%(\mathrm{n}=67)$ and $38.31 \pm 4.86 \%(\mathrm{n}=41)$; among the surveyed women permanently residing in rural areas from non-traditional factors in the development of CKD revealed a history of nephropathy of pregnant women, respectively $60.90 \pm 4.87 \%$ $(n=81)$ and $60.0 \pm 4.89 \%(n=51)$.

Analysis of the results shows that the above factors are underestimated as a risk factor for the development of CKD, and the effectiveness of preventive measures for non-communicable chronic diseases among the rural population is rather low. 
Other studied factors, such as: history of acute allergic reactions $(2.38 \pm 1.52 \%, \mathrm{n}=5$ and $13.08 \pm 3.37 \%, \mathrm{n}=14)$; chronic otitis media from non-infectious chronic foci of infection $(1.90 \pm 1.36 \%, \mathrm{n}=4$ and $5.60 \pm 2.29 \%, \mathrm{n}=6)$; history of acute bleeding or hypovolemic shock $(2.85 \pm 1.66 \%$, $\mathrm{n}=6$ and $4.67 \pm 2.10 \%, \mathrm{n}=5$ ).

Thus, the frequency of occurrence of controllable (modifying) risk factors for the development of CKD among the subjects is different, ranging from $1.90 \pm 1.36 \%$ (chronic otitis media) to $58.57 \pm 4.92 \%$ (abuse of nephrotic drugs). Of the 10 studied these risk factors, the most significant in the group of patients to establish a diagnosis based on data from outpatient cards were: abuse of nephrotoxic drugs (58.57\%), dysuria of unknown aetiology $(43.80 \%)$, abuse of salty and bitter foods (33.40\%), bad habits $(21.42 \%)$, history of proteinuria $(20.95 \%)$ and history of nephropathy of pregnant women among women $(60.90 \%)$. Almost the same tendency in the occurrence of controlled risk factors was observed in the group with established diagnoses at screening examination. From the clarified, it follows: firstly, the population permanently residing in rural areas generally has the same non-traditional risk factors for the development of CKD; secondly, a sufficiently large number of unidentified pathological conditions associated with the kidneys with the same risk factors.

For each identified patient, there are 0.51 not identified conditionally sick persons with the same manageable risk factors for the development of CKD. The detectability of controllable risk factors per patient is, respectively, from 3.40 to 4.58 risk factors. From the above, it follows that screening studies for the detection of CKD in the rural population are justified. Besides, it seems to be the basis for primary prevention of $\mathrm{CKD}$ and the basis for the development of secondary prevention of CKD among rural residents.

The next stage of research was clinical and laboratory studies in the identified contingent to establish an early diagnosis of CKD using simple, cheap, reliable, and effective laboratory diagnostic methods using urine analysis of the examined. All subjects underwent urine analysis using Combina 13 test strips (Human GmbH, Germany). These diagnostic test strips are designed to measure the semi-quantitative concentration of microalbumin in the urine. The test for measuring microalbuminuria is based on the principle of the colour change of an indicator under the influence of proteins.

Renal function was assessed in terms of the glomerular filtration rate (GFR). Normal GFR is $\geq 120 \mathrm{ml} / \mathrm{min}$. The prevalence of CKD was assessed by MAU> $10 \mathrm{mg} / \mathrm{L}$ and GFR $<90 \mathrm{ml} / \mathrm{min} / 1.73 \mathrm{~m}^{2}$. Among the examined persons $(\mathrm{n}=$ $317)$, CKD was detected in $28.70 \pm 4.52 \%(n=91)$.

The distribution of CKD by stages was as follows: stage I CKD in $7.69 \pm 2.669 \%(n=7)$, stage II CKD in $73.62 \pm 4.4 \%$ $(\mathrm{n}=67)$, stage IIIA CKD $14.28 \pm 3.49 \%(\mathrm{n}=13)$ and stage IIIB CKD $4.39 \pm 2.09 \%(n=4)$; CKD stages IV and V were not found among the examined individuals.

\section{CONCLUSION}

When analyzing the results of the study, some features related to the age and gender of the surveyed, permanently residing in rural areas, were identified. The first feature was that with the increasing age of the surveyed, the incidence of CKD significantly increases. In the group of patients over 60 years of age, the incidence was 2.6 times significantly higher $(\mathrm{p}<0.05)$ than in people aged 20 to 40 . Between the subjects aged 40 to 60 and over 60 years old - this difference was less (1.4 times), however, the indicators were significantly higher in favour of people over 60 years old $(p<0.05)$. The second feature is a gender difference, where the incidence of CKD was 2.2 times higher in women $(\mathrm{p}<0.05)$ compared with men. Studies have shown that this fact is mainly associated with the presence in the history of women of nephropathy and arterial hypertension of pregnancy. At the same time, the detection rate of nephropathy in pregnant women in history is $60.90 \pm 4.87 \%,(n=81)$ and $60.0 \pm 4.89 \%,(n=51)$, respectively; the detection rate of arterial hypertension in pregnant women was $39.09 \pm 4.87 \%$, $(n=52)$ and $40.0 \pm 4.89 \%$, $(n=$ 34 ), respectively, in the study groups. The third feature was that almost all surveyed rural women who suffered nephropathy and/or arterial hypertension during pregnancy were not observed at the place of residence (in primary health care) after discharge from maternity complexes or perinatal centres. This circumstance is also one of the important risk factors leading to the development of CKD in women.

\section{ACKNOWLEDGEMENT}

We thank the staff of the Bukhara Regional Multidisciplinary Medical Center.

Conflict of interest. We have no conflicts of interest.

Funding information. No Funding.

\section{REFERENCES}

1. Akhmedova NSh. Features of screening of renal function in an outpatient setting. Int Med J 2019;2(26):17-21.

2. Akhmedova NSh. The importance of proteinuria as a predictor of diagnosis and a factor for the development of chronic kidney ddisease. Eur Sci Rev 2018;7(8):84-85.

3. Maksimov ZhI, Maksimov DM. Screening: a modern perspective on early diagnosis and prevention of chronic non-communicable diseases. Arch Inter Med 2014;23:52-56.

4. Statsenko ME, Turkina IA. Visceral obesity is a marker of the risk of multi-organ damage. Bull Volgograd State Med Uni 2017;1:10-14. 
5. James MT, Hemmelgarn BR, Tonelli M. Early recognition and prevention of chronic kidney disease. Lancet 2010;375:12961309.

6. Gulov MK, Abdullaev SM, Rafiev KhK. Quality of life in patients with chronic kidney disease. Russian Med Bio Bull 2018;4:493-499.
7. Shvetsov MYu. Chronic kidney disease as a general medical problem: modern principles of nephroprophylaxis and nephroprotective therapy. Zh Comsilium Med 2014;16(7):51-64. 